\title{
Designing the Kè Symbol from the Chinese Bagua Symbol: The Case of the Bamilekes of Western Cameroon
}

\author{
Djoukwo Tsanetse Majolie Carine ${ }^{1}$, Aihong Wang ${ }^{2}$, Elise Limunga Linda ${ }^{3}$ \\ ${ }^{1}$ International College Department, Jingdezhen Ceramic Institute, Jingdezhen, China \\ ${ }^{2}$ Department of Products Design, Jingdezhen Ceramic Institute, Jingdezhen, China \\ ${ }^{3}$ Department of Environment Science, China University of Geoscience, Wuhan, China
}

Email address:

L20180902@stu.jci.edu.cn (E. L. Linda),cdjoukwo@gmail.com (D. T. M. Carine)

\section{To cite this article:}

Djoukwo Tsanetse Majolie Carine, Aihong Wang, Elise Limunga Linda. Designing the Kè symbol from the Chinese Bagua Symbol: The Case of the Bamilekes of Western Cameroon. English Language, Literature \& Culture. Vol. 6, No. 2, 2021, pp. 24-36.

doi: $10.11648 /$ j.ellc. 20210602.12

Received: April 15, 2021; Accepted: May 5, 2021; Published: May 14, 2021

\begin{abstract}
Among the Bamileke tribe in the West region of Cameroon, is a unique phenomenon known as Kè. That is a demonstration of spiritual, philosophical, religious, and magical concepts. A similar concept exists in China, expressed by the divinatory symbol of "Bagua," or "eight figures of divination." It is a basic philosophical idea from ancient China that was incorporated into "Taoism," "Yi Jing," "Feng Shui," martial arts, and navigation. The Chinese term denotes an octagonal diagram incorporating a "trigram" different from each side, representing the different aspects of the "Yin" and "Yang". Inspired by this concept of duality, we have set up a method of artistic creation allowing both juxtapose and merging the symbolic elements of the local Bamileke culture, especially those involved during Kè ceremonies. The method consists of associating the signs and symbols relating to the man and the woman concerning Yin and Yang and merging the local signs regarding trigrams. The goal is to translate the idea of complementarity that emerges from the Chinese symbol using the elements of the Bamileke crop. These multiple compositions lead to a series of figures that are similar to the Bagua symbol in their central parts. As for the four branches that contain mergers, they are inspired by the Bamileke divinatory symbol which is none other than a stylized Mygale spider. Because of their structures, these different proposals reflect the concept of Kè in the Bamileke and can validly represent it. It can therefore be appreciated on different objects and other supports put to contribution for the smooth running of the related festivities.
\end{abstract}

Keywords: Kè, Bagua, Bamilekes, Yin-Yang, Yijing

\section{Introduction}

In the same way that transcendence, power, and dynamism dominate all and everyone in a mystical yet fruitful way, $k e ̀$ is a spiritual concept that derives as much from spirituality as it does from religion and magic. Many associated with this phenomenon are the most feared works of art, the mere sight of which is also forbidden. Father Maillard posits that experiencing $k e ̀$ is to allow and accept a new thought about living. There is an initiation to a new experience, more spiritual than logical, beyond the consciousness of a power that is admitted by itself.

In the Chinese culture, there is a symbol whose meaning, use and function correspond in many ways to the concept of $k e ̀$ among the Bamileke people of West region of Cameroon known as the divinatory symbol of Bagua. It is a fundamental philosophical concept of ancient China used in Taoism and Yi Jing, but also in other areas of Chinese culture, such as feng shui [1], martial arts [2] or navigation. In Chinese culture, especially in Taoism, it is an esoteric concept of Chinese Taoist culture [3], and a set of metaphysical philosophical symbols made up of four groups of Yin and Yang. [4]

This transformative philosophy discusses natural and social phenomena. According to the Bamileke ${ }^{1}$, animals can even "see" to the extent that the immortal regents of all around us use them to predict the future. Among the animals

\footnotetext{
${ }^{1}$ They are the people of the grassland, located in West Cameroon.
} 
most famous for this initiative, we have the Mygale spider. During the festivities as a prelude to the unfolding of the $k \grave{e}$, the Bamileke regularly consult this animal. $K \grave{e}^{2}$ is not a figurative concept, recognizable through particular signs and symbols as it is the case of Bagua [5] of China through Yin and Yang for example.

It is still part of a well-preserved traditional concept passed down from generation to generation. Although it is an object of curiosity for many national and international researchers, it must be said that with the exception of the art objects with which this phenomenon is associated, there is no particular figurative form allowing it to be identified or even to characterize it. Initiating a process of artistic creation in order to design symbols referring to kè will be the subject of this study.

The approach is inspired by both the Bagua and the Bamileke divinatory symbol, materialized by the Mygale spider. To carry out this research, it is important to give an overview on the concept of $k \grave{e}$ among the Bamileke of western Cameroon, the Bagua of China [6], and finally, the methodology of conception of the works proper will be presented.

\section{The Bamilekes People and Their Culture}

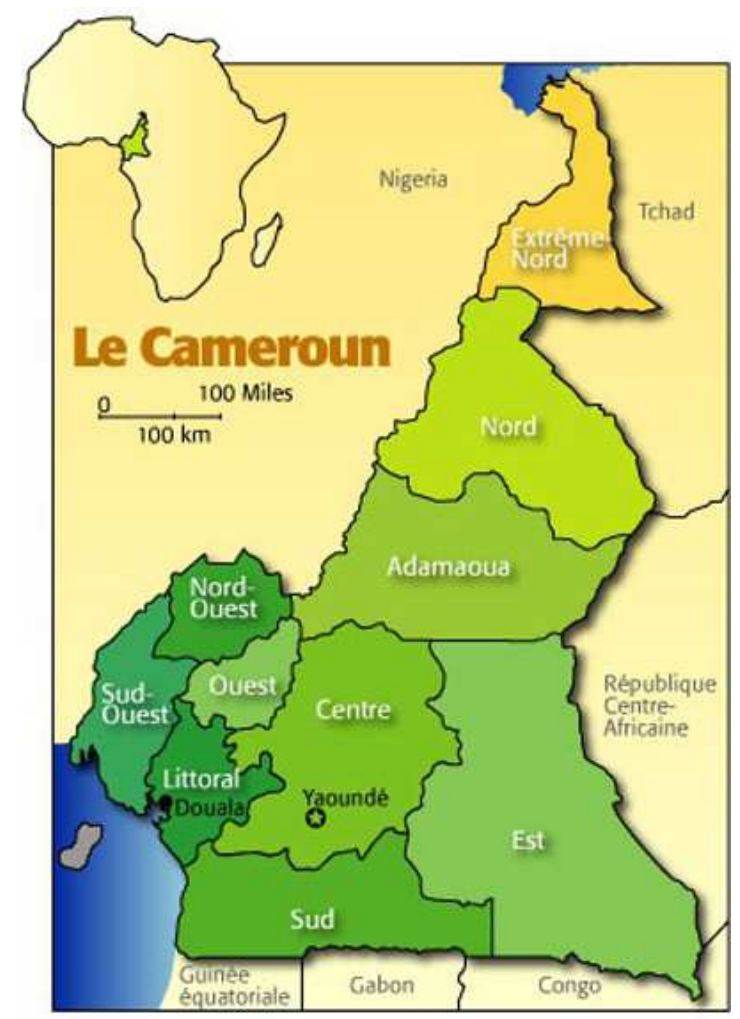

Figure 1. Cameroon and its position in Africa, reproduced from the embassy of the Republic of Cameroon in Japan website.

\footnotetext{
${ }^{2}$ The power of the cosmos in the Bamileke.
}

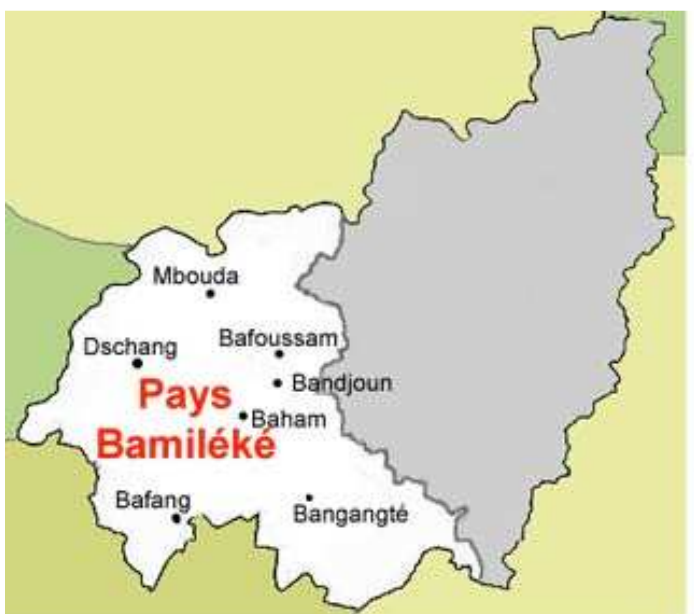

Figure 2. The Bamileke chiefdoms of West Cameroon (Source: MarieDominique NENNA, Jean-Yves EMPEREUR, CNRS (USR 3134) Alexandrian Studies Center, 2013).

The Bamileke are a people who live in the Grassfield ${ }^{3}$. They are Cameroon's largest ethnic group, occupying the country's western and northwestern regions. The Bamileke are split into a series of groups, each directed by a chief or fon. They speak a number of related languages from the Eastern Grassfield branch of the Grassfield language family. These languages are however closely linked, and some classifications identify the Bamileke dialect continuum with seventeen or more dialects. The Bamileke people [7] are known for their very striking and often finely beaded masquerades, including impressive masks of elephants.

\subsection{Brief History of the Bamileke of West Cameroon}

The Bamilekes form the largest ethnic group in Cameroon (20\%). Together with the Tikar and the Bamoun, they make up the Semi-Bantu [8] group. They inhabit the western Cameroonian province and speak semi-Bantu languages more or less close to each other (including Yemba, Ghomala,

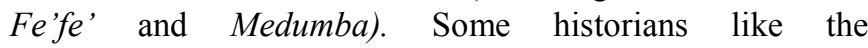
Cameroonian, D. Toukam posited that the Bamileke are "neoSudanese". His work concludes that the Bamileke would most likely come from the Baladis ${ }^{4}$ of Sudan.

The current Feelahins / Copts are largely recognized as Baladis converted by force, but still retaining huge parts of their ancestral culture. Leaving from Upper Egypt in the 9th century AD [9], the Baladis-Bamileke arrived in the Tikar region in the 12th century. The people of the Grassfields, who spoke a single language and had a single chief, dissolved about 1357 when their last supreme ruler, King Ndeh, died. Yende, the first prince and future king, turned down the role as the new paramount ruler and established Bafoussam across the Noun river.

His sister turned to the region of Banso (there are 123 Bamileke groups in the English-speaking North-West and 5 in the South-West - Lebialem). Nchare, the youngest, went

\footnotetext{
${ }^{3}$ Volcanic highlands located in the west of Cameroon.

${ }^{4}$ People of Egyptian origin where the Bamileke would have.
} 
down to the Noun plain and discovered the nation of Bamoun two decades later. The majority of today's big Bamileke groups descended from Bafoussam, and the transition continued from the 15 th to the 20 th centuries.

\subsection{Presentation of the kè Among the Bamileke}

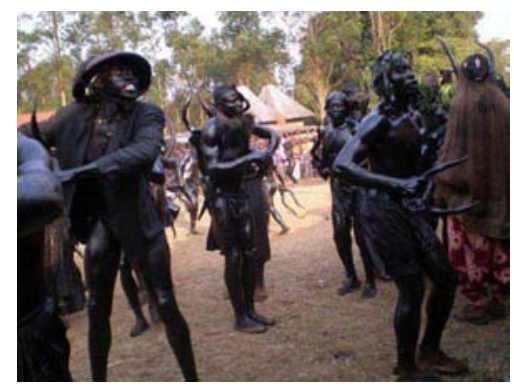

Figure 3. Initiates in a parade on the occasion of the kè.

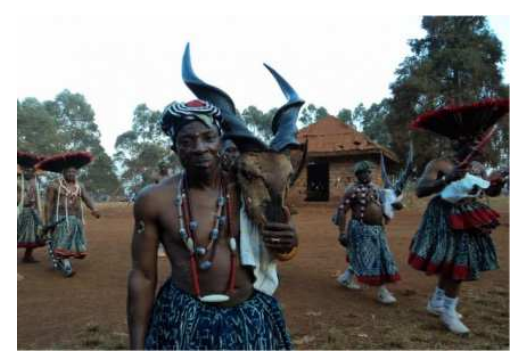

Figure 4. Member of a secretive society during kè festivities.

The art historian Jean Paul Notue [10] affirms that kè is a magico-religious phenomenon which is a fundamental aspect of the Bamileke' royalty and an important base of their social organization. The earliest practises associated with it date all the way back to the fourteenth century. In addition, the supernatural strength of all Bamileke $f o$ and certain objects symbolizing its power (the case of the double bell) is attributed to kè. When confronted with the otherworldly beings of spirits and the supernatural forces that surround them from all sides, the Bamileke takes one of two positions; On one hand, they attempt to sway these (more or less evil) forces in his favour which explains all the sacrifices and cults directed at the supreme being, whether directly or indirectly through their ancestors and gods. In the other hand, they seek to discover the secret of these mysterious forces in order to seize their power and authority over others: this is the approach taken by magicians and wizards. As a result, magic tends to be an attempt to understand the cosmic powers that lie dormant in everything and that can be conquered. It's just a transfer of vital powers and all the dynamism, which is the essence of black religions.

Questioned by Jean-Paul Notue, the notable Mr. FOUOWOUM from Bagang (Bamileke village), who is also responsible for the society of men-hawks, affirms about kè: 'this power is invisible and immaterial. Matter is only one of its seats among so many others: air, speech, rainbow, wind, etc. It is defined by its spectacular actions. The theory of powers, of transcendental forces is general in Africa, but its nature differs from one region to another.'

SAVARY (C) says:
"Among the Bamileke there are a large number of rites intended to maintain the fertility of the group, which are addressed either to the ancestors or to the local deities. All this necessarily leads to magical acts or practices, inseparable from religious beliefs. The proof is for example that the term kè, which is used to designate all that has a magic side, represents at the same time an important agrarian rite and the rite of passage for adolescents. " [11]

Initially, according to Charles Henry Pradelles of Latour, kè or kang always started in March or April, sometime after sowing, on the evening of the first day of the week. The Bamileke year, which correspond to an agrarian cycle, is divided into eight-day weeks with no months. Tenguéla' (the chief priest) stands at the foot of the sacred tree in the palace, called küpkang, or "where kang comes from,"during this ritual. There, he cooks beans with palm oil in terms of engaging the gods to release a beneficial force called kang.

The chief and six descendants of brothers of former chiefs, named "fathers of the kang", were to repeat this sacrifice in the sacred forest. There, at the foot of a sacred tree, representing the god of the country, they left food and a male drum. When the chief and the fathers of the kang took the way back, they should not look back. Then the god of the country struck the drum to let him know that he agreed to bring out the kang from the ground. The god of the country was represented by Tenguéla 'who was going to hide in the forest as soon as he had sacrificed to the palace.

The sound of the drum announced the start of the inaugural nine weeks of the biennial cycle. One of the kang fathers would then pick up the drum and bring it back to the chiefdom's dance floor so that the people could dance for the kang. From then on, women were no longer required to plant their hoes in the ground, and the people were no longer permitted to use the gods as witnesses for judgments, marry children, or mourn the dead. During this period, the main lineage activities were suspended so that the village could be regenerated by kang.

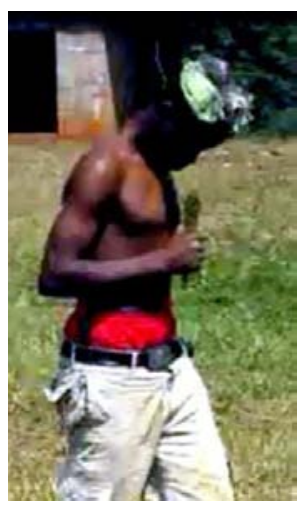

Figure 5. Young teenager newly introduced to kè.

Teenagers, representing the rising generation who came to renew the society of adults, were in the spotlight. The day before the second day of each of these weeks, the boys who had reached the age of ten went shaved heads, in small groups of seven or eight, to one of the kang's fathers who had 
accompanied the chief to the forest. After having swallowed a certain type of food by following a certain ritual, the adolescents washed, coated their bodies with red powder, [12] made themselves a few spots of kaolin, tied around their kidneys a loincloth made of raffia fibres, took the horns of 'a cob of Buffon and gathered in the main square of the palace while singing.

In the presence of the chief and the audience, they performed dances. The order of the dance groups was established by the conductor. This dance was a great event. The nine notables and the chief's friends went to the chiefdom to dress in their traditional clothes. [13] They hung one or two panther skins on their backs, covered their faces with a canvas mask in the shape of a richly decorated elephant [14] head and put as a headdress a carved wooden crest or a large hat bordered with red parrot feathers. They went out around three in the afternoon with great fanfare under the enthusiastic cheers of the population.

The dancers waved their fly swatches in a ponytail and handed them to women or friends of their choice who found themselves mixed with the people gathered on the edges of the square. The chosen one took the trophy, pushed an acute ulceration and returned it to its owner. The conductor finally made a particularly noticeable appearance because he was the only dancer without a mask. The cheers increased and the excitement reached its peak. The chef danced several times during the ceremony around the main square accompanied by other dancers. This colourful event ended the nine-week kang period.

The boys' rite of aggregation into society lasted only twentyfour hours. It was practiced on the second day of the first weeks of kang. The markets were not interrupted during this period. The function of this rite was to consolidate the social unity of the country by reinforcing the dependence of the younger generations on the lineage of the chief and thereby on the chiefdom, whose prestige was enhanced.[15] Indeed, only the chief and the members of his lineage could ask the gods of the village to release the $k \grave{e}$, because this god was first the tutelary power of their lineage before being that of the country.

By undergoing the rituals of $k \grave{e}$, the adolescent thus became a worthy son of his country [16], it was there that he was transmitted traditional knowledge and respect for custom. Even today, the activities marking the celebration of $k \grave{e}$ are effective in the Bamileke tribes, but given their dynamic nature, they vary from one arrondissement to another, and undergo changes over time. Among the Baleng, for example, kè is its biennial period of culture, a moment of reunion, rejoicing, initiation of young boys at least ten years of age and of the women who gave birth to twins.

The period spans almost three months. Among its major articulations, the weekly parade of the various secret societies, an agro-pastoral show, an artistic evening with the election of the Miss Baleng on the square of the chiefdom. This festival was also the occasion to sensitize the peoples of the western region, precisely those of Baleng against the dangers of AIDS [17]. Celebrating the culture and preserving the health of the Baleng people is the aim of this great cultural event in the West Cameroon [18]. Louis Perrois and
J.P. Notue were interested in the Ngou-Ngoung rituals called gnan-gnan in the Baleng kingdom [19]. These rituals are a form of expression of $k \dot{e}$.

Since it comes from the supernatural, from the divine, $k \grave{e}$ has the particularity that it constitutes a transmission belt between the Bamileke and the gods of his tribe. In addition, the notion of kè reveals the dependence of the Bamileke on the forces of nature for better productivity on the agricultural level, better security on the magico-religious level, the duality between the creator and the created being. From this point of view, the concept of kè could come close to that of Bagua ${ }^{5}$ from China.

\section{The Divinatory Symbol in Chinese Culture}

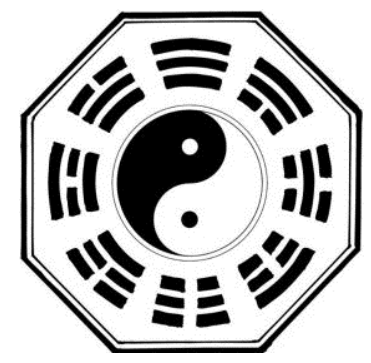

Figure 6. Primordial form of FuXi Bagua.

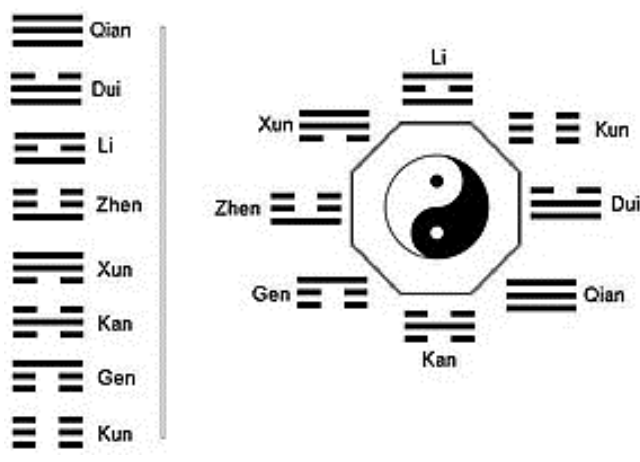

Figure 7. Bagua of the Succession of the posterior sky.

It is a fundamental philosophical concept of ancient China used in Taoism and Yi Jing ${ }^{6}$, but also in other areas of Chinese culture, such as feng shui, martial arts or navigation.

\subsection{Origin of Bagua}

The first would be the traditional philosophy of Yin-Yang ${ }^{7}$. The relationships between these two philosophies have been described by Fuxi ${ }^{8}$ in these terms:

\footnotetext{
${ }^{5}$ Eight divination figures, Ba gua, Bagua or Pa Kua is an octagonal diagram with a different trigram on each of its sides.

${ }^{6}$ Chinese manual "Classic of changes" or "Canonical treaty of changes" or "Book of transformations". It is a binary sign system that can be used to make divinations.

${ }^{7}$ The two opposing principles in nature which refer to man and woman.

${ }^{8}$ Fuxi or Fu Hsi is a mythical character in Chinese mythology whose origins go back to antiquity, civilizing hero, chief of the Huaxia people, founder of traditional Chinese medicine, creator of Chinese characters, and the first god of the three Augusts.
} 
Table 1. Relationships between Yin-Yang, by Fuxi.

\begin{tabular}{ll}
\hline Hànyŭ pīnyīn & Translation into English \\
\hline Wúji shēng tàijí & Nothingness (wuji) begets the Absolute (taiji). \\
Tàiji shēng liăng yí (jí yīn yáng) & Taiji generates two forms (yin and yang). \\
Liăng yí shēng sì xiàng (jí shàoyáng, tàiyáng, shàoyīn, & The two forms generate four phenomena, that is to say small yang, large yang (taiyang also \\
tàiȳn) & means "sun"), small yin, large yin (taiyin also means "moon"). \\
Sì xiàng shēng bāguà (bābā liùshísì guà) & The four phenomena generate the eight trigrams (eight times eight is sixty-four hexagrams). \\
\hline
\end{tabular}

A possible source would be Emperor Wen of the Zhou dynasty: "When the world began, there was Heaven and Earth. Together, they gave birth to everything that exists on earth. Heaven is Qian-gua, and Earth is Kun-gua. The other six gua are their children."

In ancient Chinese philosophy, Yin and Yang, "Darkbright", ("negative-positive") is a concept of dualism, describing how apparently opposite forces can in fact be complementary, interconnected and interdependent in the natural world, as well as the way they can occur mutually when linked to each other. In Chinese cosmology, the universe is created from a primary chaos of material energy, organized in cycles of Yin and Yang and formed into objects and lives [20].

Yin is the receptive and Yang the active principle, seen in all forms of change and difference such as the annual cycle (winter and summer), the landscape (shade towards the north and luminosity directed towards the south), sexual coupling (feminine and masculine), the formation of feminine and masculine characters and socio-political history (disorder and order). There are different dynamics in Chinese cosmology. In the cosmology of Yin and Yang, the material energy from which this universe was created is also called qi. It is believed that the organization of $q i$ in this cosmology of Yin and Yang has formed many things.

Among these forms are humans. Many natural dualities (such as light and dark, fire and water, expansion and contraction) are considered to be physical manifestations of the duality symbolized by Yin and Yang. This duality is at the origin of many branches of classical Chinese science [21] and philosophy, in addition to being a main guideline of traditional Chinese medicine [22] and a central principle of the different forms of martial arts and Chinese exercises [23], such as baguazhang, taijiquan, (t'ai chi) and qigong (Chi Kung).

The concept of duality is found in many areas, such as communities of practice. The term "dualist monism" or dialectical monism was coined to try to express this fruitful paradox of simultaneous unity and duality. Yin and Yang can be thought of as complementary (rather than opposing) forces that interact to form a dynamic system in which the whole is larger than the assembled parts. According to this philosophy, everything has both Yin and Yang aspects (for example, the shadow cannot exist without light).

Either of the two major aspects can manifest itself more strongly in a particular object, depending on the criterion of observation. The Yin Yang (the taijitu symbol) shows a balance between two opposites with a part of the opposite element in each section. In Taoist metaphysics, the distinctions between good and evil, as well as other dichotomous moral judgments, are perceptual and not real; thus, the duality of Yin and Yang is an indivisible whole. On the other hand, in the ethics of Confucianism, especially in the philosophy of Dong Zhongshu (around the 2nd century BC), a moral dimension is attached to the idea of Yin and Yang.

\subsection{Description of Each Trigram}

It should be noted here that the description is attributed to the school of the golden lion ${ }^{9}$, founded by the last descendant of the school of the white lotus, school to which is attached the society of the eight trigrams [24].

K'IEN: The Creator. The creator is said to be the most powerful in the world. Its symbolic animal is the horse. As symbols, the sky, the father, the jade, the cold, the ice, the metal, the dark red, the dragon, the outer garment, the word, the prince, the precious stone, the round, the gold. All these notions which seem dispersed and contradictory are confirmed by the prints; they are necessarily symbolic.

$K^{\prime} O U E N$ : The Receptive. The receptive is the earth, the mother, passivity, the dark, the crowd, the darkness, a fabric, the cauldron, the economy, the calf with the cow, a large chariot, the shape, the multitude, the child, the yellow, the skirt, the fly, the square, the bag, the trunk. From a symbolic point of view, the earth supports life like a fabric, a garment. The mother takes care of food, an essentially lunar function. The moon shines at night; the calf and its cow are symbols of fertility, and so on.

TCHEN: The Waker. The Yang and the Yin were perfectly figured, at their extreme, in the two previous trigrams. It was the most extreme of the masculine (K'ien) and the most extreme of the feminine (K'ouen). The symbolism of the continuous lines evoked the male and its organs of generation by which life continues. That of the discontinuous lines, cut, hole, cavity, folds, runoff, the female genital organs, into which the germ descends, where it develops, and where the child comes into the world and breath of life.

The Awakener is the eldest son, the young and green bamboo, the rush, the reed the movement, the thunder, the dark yellow, what stretches, the dragon (mythical animal), the decision, the vehemence, feet, shaking, drum, coming back to life, the crow, which is strong and grows luxuriantly.

$K^{\prime} A N$ : The Unbeatable. The solid line, Yang, is between two Yin lines, which besiege and undermine it. You should

\footnotetext{
${ }^{9}$ The school of the golden lion, Pai Liang Qiao association, was founded in 2014 by Philippe Reus, pupil of the master Hu Dong Liang, last descendant of the school of the White Lotus.
} 
not believe that this trigram is "bad". The spelling of $K^{\prime} A N$ designates a plant and, to its right, next to it, puffs spewed out of a mouth, which can be a cavity, an abyss, a cave, like formerly Delphi, a mouth of which the Orphic mysteries constituted an element and a necessary, religious and sacred processes.

The vapours emitted from this »mouth. $K^{\prime} A N$ is the ear, the pits, the trap, the bow, the arrow, the occult, the secret, the thief, the moon, the withdrawn apartment (interior), the red, the calamities, the evils ear, melancholy, heart discomfort, water, pork, ditch, fox. Pitfall, detour, indecision.

$K E N$ : Immobilization. The trigram reading from bottom to top, we see the yin lines (open in their center) let the current of forces pass, which immobilize against the yang line, weighing on the whole, and bringing total immobility and rigidity. Firmness, solidity, stopping, permanence, result from it. The diagram shows an eye above a standing man. Ken rules the immobilization, the dog, the rat, the black-billed birds, the roundabout, the doors, the stones, the openings, the fruits and seeds, the mountain, the monk, the nose, the eunuchs, the guardians, solidity.

Analogously, the diverted paths are those of mountain paths, the guards immobile near the doors are a figure of rigidity.

SOUEN: Soft. Transcribed phonetically, too, HSUAN or SOUN. On either side of the table top, two mandarins are in discussion (they hold a seal, part of which, as proof, remained SOUEN, the gentle, represents the eldest and adult daughter, work, white, up, along, forward and backward, indecision, the act of entering, haste, broad forehead, the hen, the smell, the thigh, the wood, the wind, the elevation, an imminent profit, the branch of the tree, the weft of the fabric, the hard-working men, the vehemence, men with gray hair, the cord, among others.

$L I$, what adheres, what is attached. Its spelling represents a yak, a draft animal that we see on the highlands, and which replaces our ox. Just as on our astrological plane, the bull is a sign of strength, of increase (these provided by the flesh and nutrition: Venus / Moon, the masters of the sign) we find here the essential idea of strength. $L i$ is what gets attached, the fire, the younger girl, the breastplate, the helmet, the drought, the turtle, the crab, the snail, the mussel, the spears, the weapons, the sun, the lightning, approximation or separation, pheasant, eye, posterity, reptiles, prominent belly.

TOUEI or TUI: The Merry. It is the lake, the youngest girl, the mouth, the tongue, the throat, a magician, to crush and break in multiples, to fall, to spring, the serenity, the sentence of justice, the balance, the little girl, the swamp, the ram, the duty, the decision in union or separation, the harshness, the concubine, the sheep, the pleasure.

\section{Design of Kè Symbols}

In order to provide answers to the problem, the process is as follows:

\subsection{Process Statement}

A study of the content of the different parts of the Bagua trigram as described above, by finding images to which they could relate in the Bamileke culture [25] in relation to the rituals of $k \grave{e}$.

The presentation of some Bamileke and Bantou symbols is general to represent the concept of male / female duality with reference to the Yin and Yang of Bagua.

The use of an artistic creation method established by a famous Cameroonian artist Pascal KENFACK [26] in the context of mergers.

Design and production

\subsection{Representation of Sketches}

Images to which parts of the Bagua trigram could correspond in the Bamileke culture in relation to the rituals associated with kè.

SOUEN, natural image the wind, Bamileke symbol, tree branches.

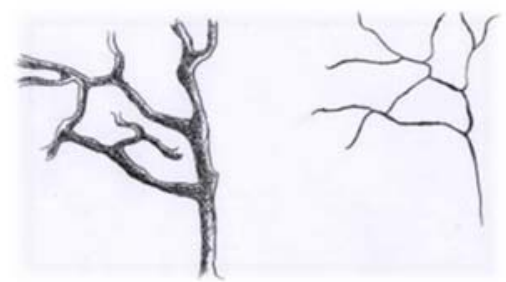

Figure 8. Branches of trees that represent SOUEN, Djoukwo, 2020.

KEN, natural element, the mountain. Symbol Bamileke, the chief keeper.
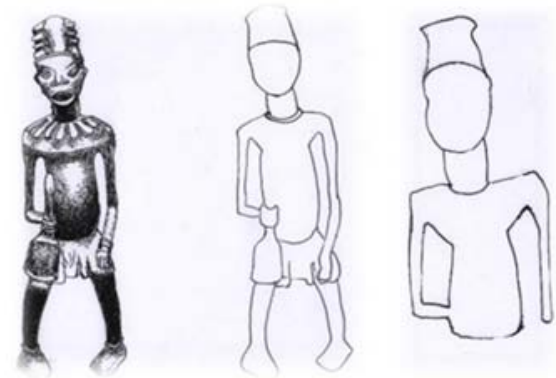

Figure 9. The keeper of the fo which here represents the Ken, Djoukwo, 2020

TOUEI ou TUI, natural element, the swamp, symbol Bamileke, the three stones of justice.

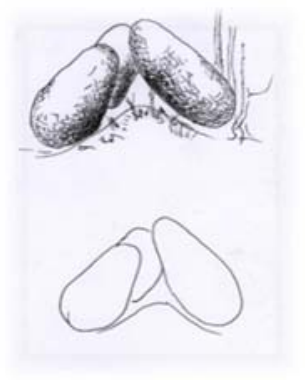

Figure 10. The three Bamileke justice stones, which here represent Tui, Djoukwo, 2020. 
Tchen, natural element, thunder, Bamileke symbol, the drum.

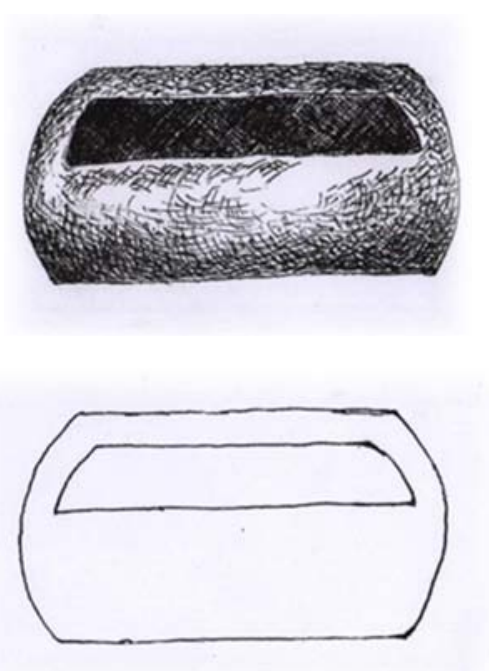

Figure 11. The Bamileke drum, which represents Tchen, Djoukwo, 2020.

In the next part, the symbols presented will conform to the Bamileke artistic expression and therefore to the art of the Bantu people in general. Bantu art (sculpture, music, dance) is inseparable from religion [27]. It is the expression of an esoteric and traditional symbolism which makes the invisible more than the visible. The Bantu works serve to harness wild energies and make them thus favourable to the whole group [28].

The use of the Bamileke symbols (and Bantou in general) to represent the duality between men and women.

Men symbols

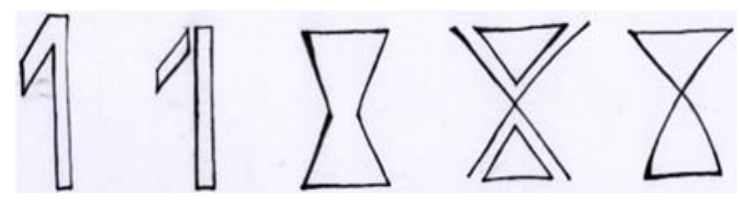

Figure 12. Symbol of man in the Bamileke.

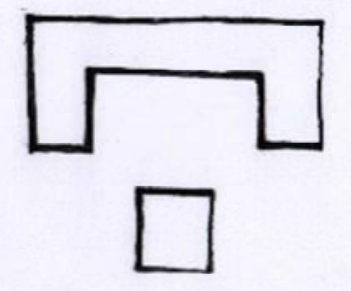

Figure 13. Symbol of the spirit in the Bamileke.
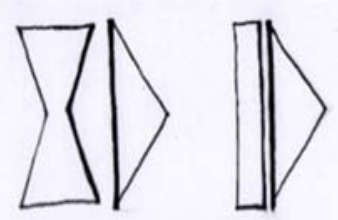

Figure 14. Symbol of the warrior and his shield among the Bamileke.

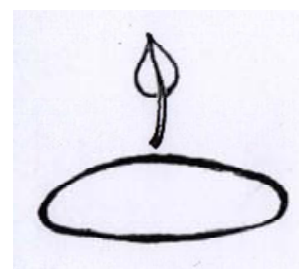

Figure 15. Symbol of the chief among the Bamileke.

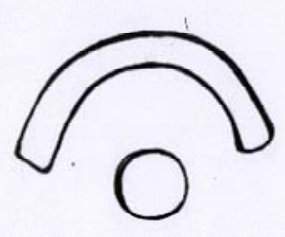

Figure 16. Brain symbol in Bamileke.

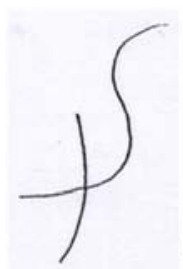

1

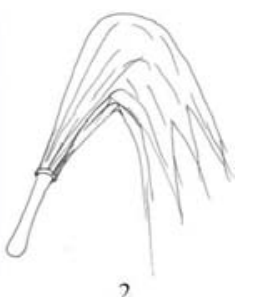

Figure 17. (1). The Chinese character «strength», (2) the ponytail refers to the man, Djoukwo, 2020.

The symbols of women

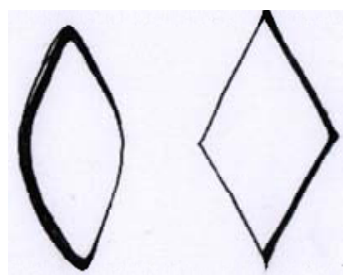

Figure 18. Symbols of women in Bamileke art.
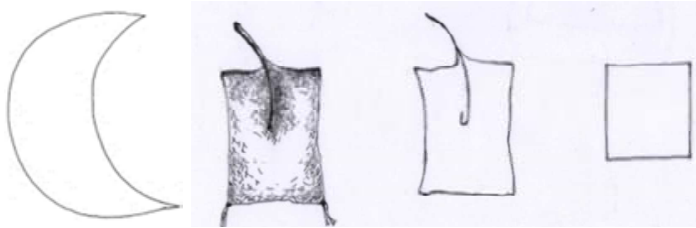

Figure 19. The moon, an ox horn, a Bamileke bag and a square, which refer to the woman, Djoukwo, 2020.

Due to the elements of various orders suggested by the analysis of Bagua trigrams, we have attributed certain forms to both men and women. Thus, the Chinese character "power" (figure 17) as well as the ponytail could symbolize the man, while an ox horn, a traditional Bamileke bag, the moon and a square shape could symbolize the woman.

The use of an artistic creation method established by a famous Cameroonian visual artist Pascal KENFACK ${ }^{10}$ in the context of mergers.

\footnotetext{
${ }^{10}$ Dr. Pascal KENFACK is a teacher-researcher in visual art in Cameroon.
} 


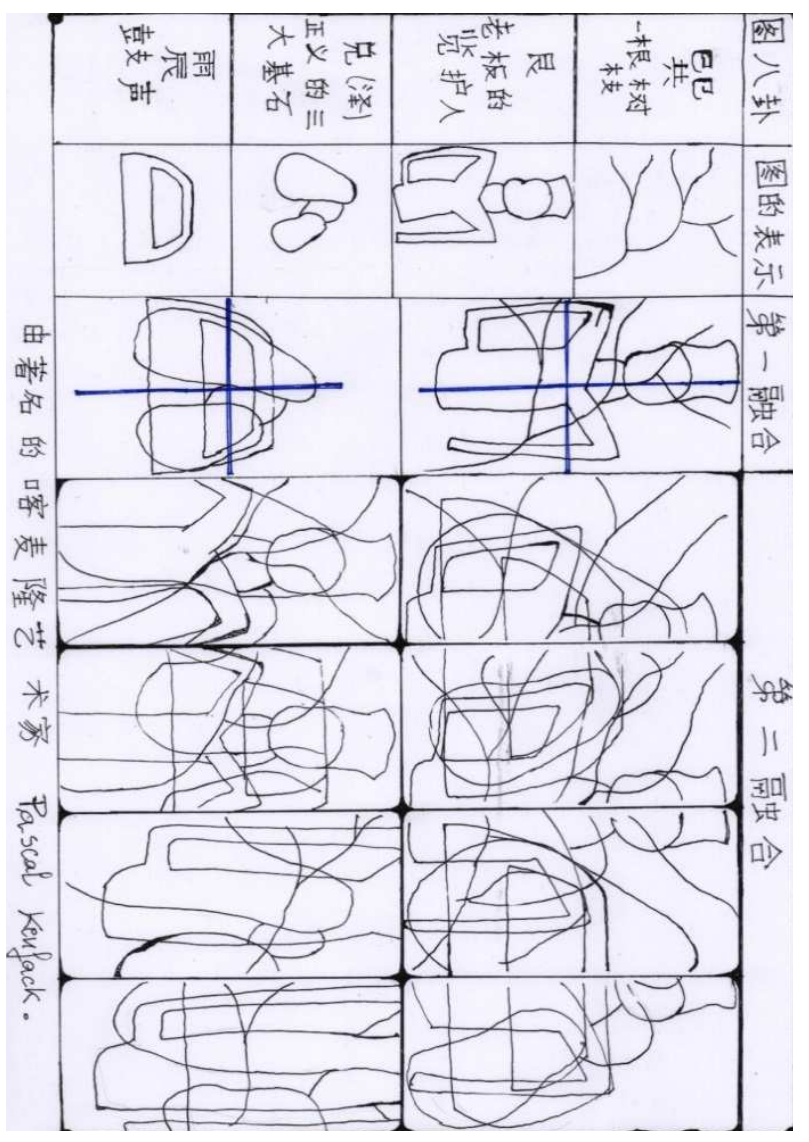

Figure 20. Study sheet for merging the sketches obtained based on the trigrams xun, gen, tui, tchen, Djoukwo, 2020.

\section{Symbols Creation}

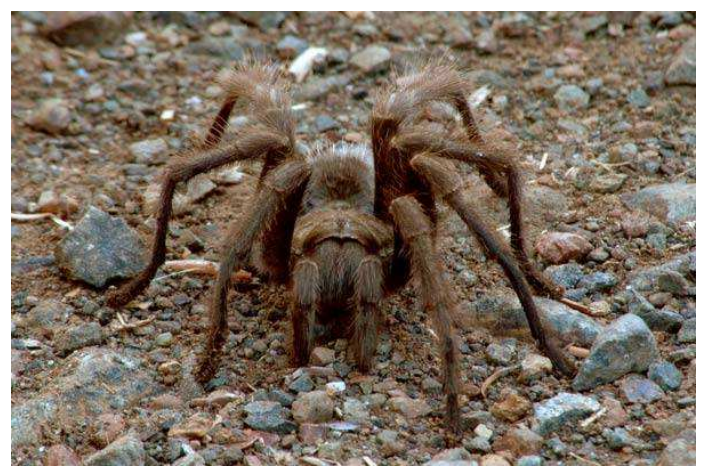

Figure 21. The Mygale spider.

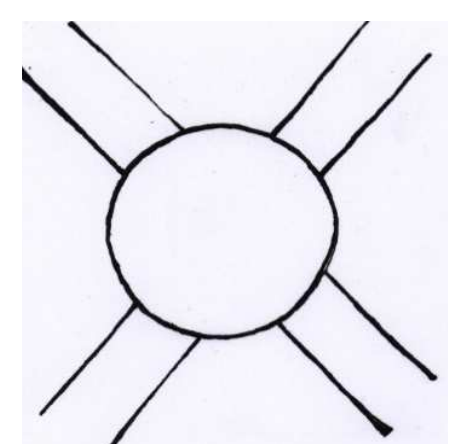

Figure 22. The Mygale spider, symbol of divination among the Bamileke, Djoukwo, 2020
The symbol of divination among the Bamileke is a stylized Mygale spider. Associated with the divinatory symbol Bagua in an arrangement of the sketches obtained at the end of the previous mergers, one could end up with the symbolism of $k \dot{e}$ among the Bamileke.

\subsection{Presentation of the Sketches}

Symbols of kè, association man / square, spirit / bag.
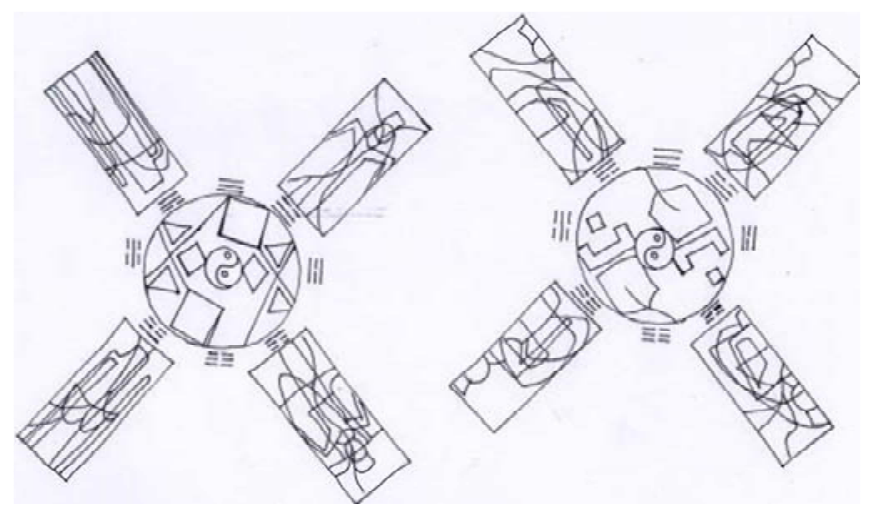

Figure 23. Symbols of kè, association man / square, spirit / bag,2020.

Symbols of kè, association spirit / woman, brain / woman.

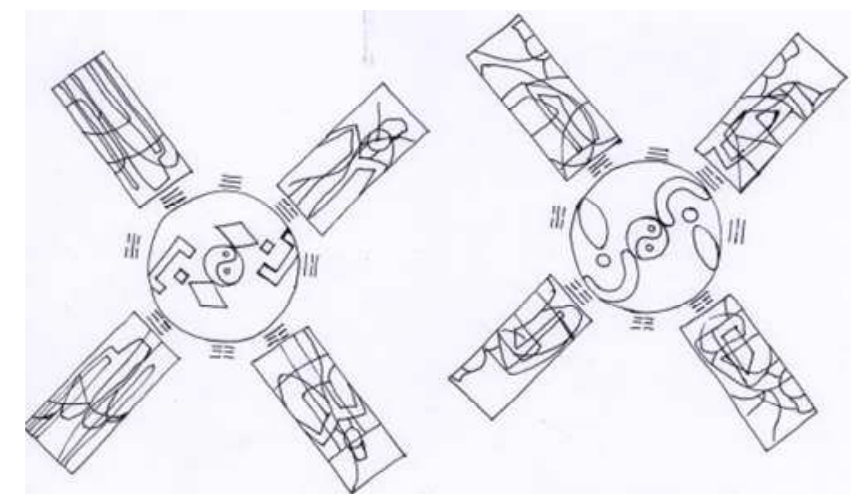

Figure 24. Symbols of kè, association spirit / woman, brain / woman, Djoukwo, 2020.

Symbols of kè, association brain / square, warrior / woman.

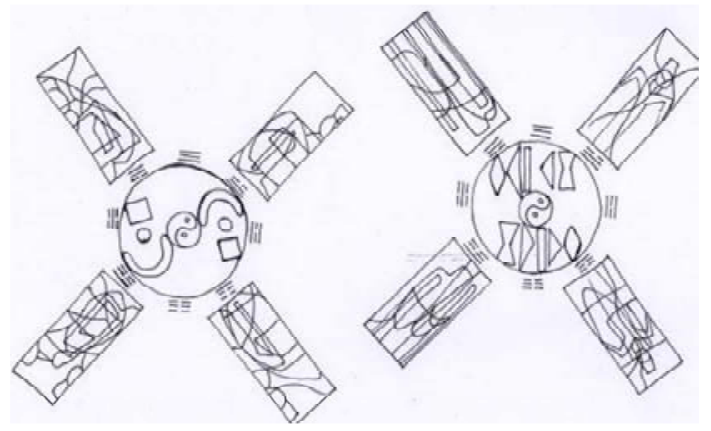

Figure 25. Symbols of kè, association brain / square, warrior / woman, Djoukwo, 2020.

Symbols of kè, association man / woman, brain / bag. 


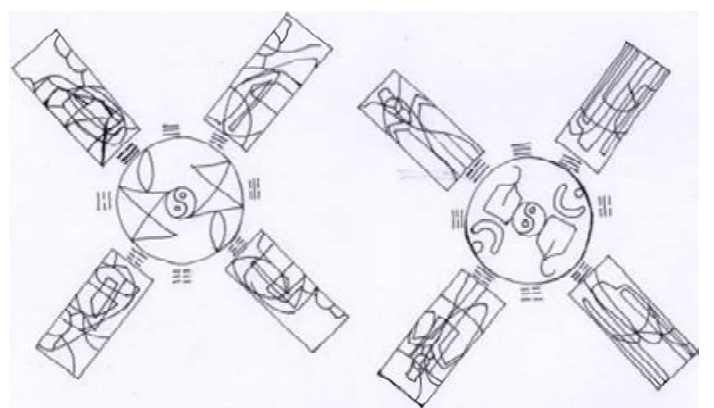

Figure 26. Symbols of kè, association man / woman, brain / bag, Djoukwo, 2020.

Symbol of kè, association spirit / square, spirit / woman.

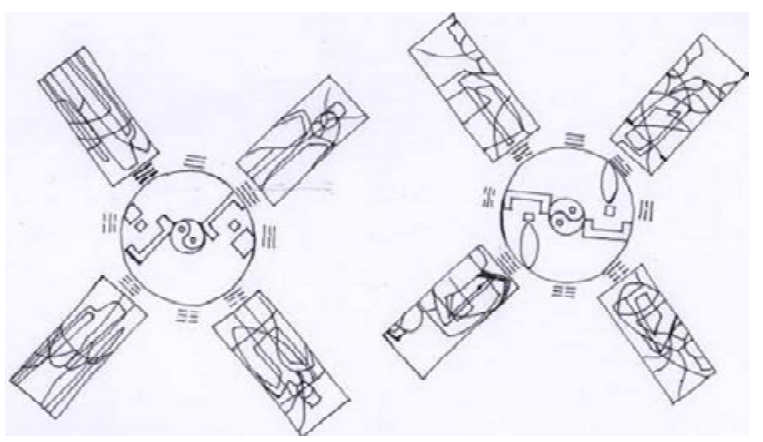

Figure 27. Symbols of kè, association spirit / square, spirit / woman, Djoukwo, 2020

Symbols of kè, association man / woman, spirit / woman.

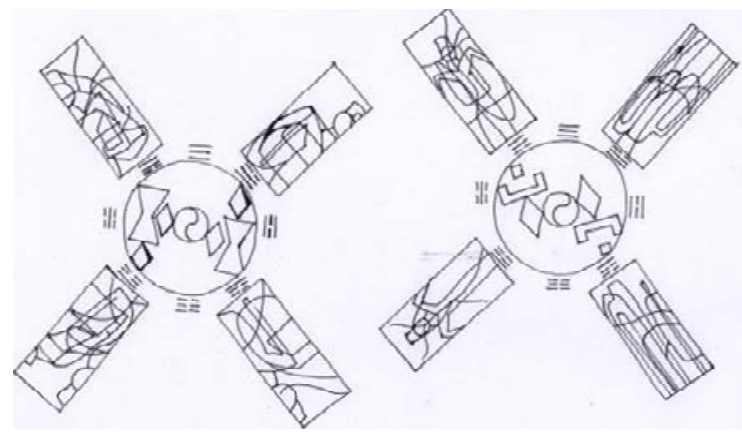

Figure 28. Symbols of kè, association man / woman, spirit / woman, Djoukwo, 2020.

Symbol of kè, brain / woman association.

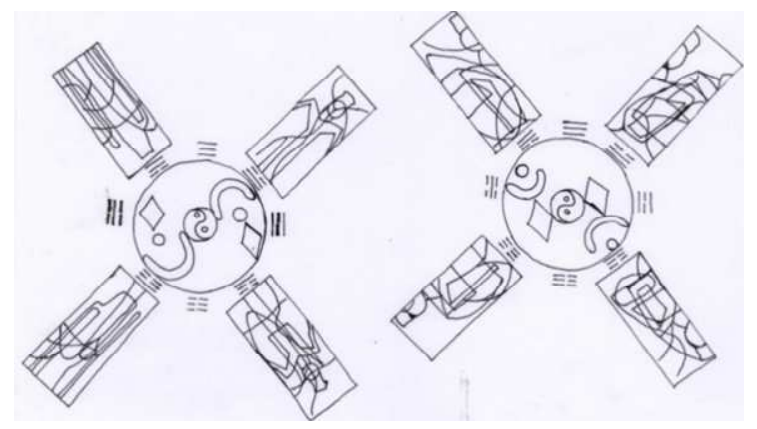

Figure 29. Symbol of kè, brain / woman association, Djoukwo, 2020.

kè symbol, chief / woman, man / woman association.

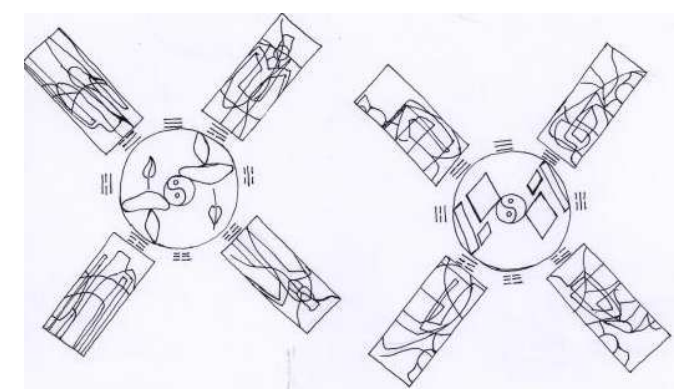

Figure 30. kè symbol, chief / woman, man / woman association, Djoukwo, 2020

\subsection{Description and Analysis of Two Symbols}

In his works, Panofsky [29] defines three stages of iconographic / iconological study. These steps will allow us to decipher the intrinsic values of the tables. The first step is the pre-iconographic analysis. We examine the work within the stylistic field by replacing it at the time indicated by the way it is treated. The second step is the Iconographic Analysis. The elements that accompany the work are taken into account, its different attributes or characteristics, following the precepts that this method requires.

The third step is the Iconological Analysis. The work is examined in relation to its cultural context, trying to understand its meaning at the time of its conception. We are therefore in the interpretation of the work. The following analysis will be based on this third step of the methodology.

Symbol of kè, ponytail / moon association

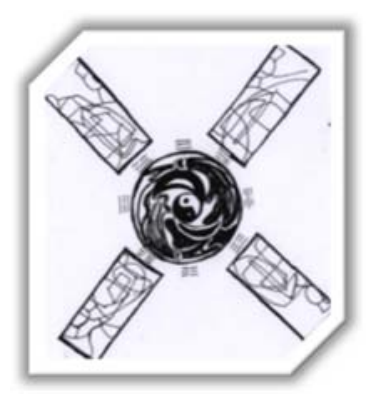

Figure 31. Symbol of kè, ponytail / moon association, Djoukwo, 2020.

Due to the presence of the trigrams as well as the Yin-Yang, we can say that this image is inspired by the Bagua of China [30]. Given its four arms, it must be said that it is also inspired by the symbol of the Mygale spider in the Bamileke. By analogy to Bagua, we find the concept of duality in its center, through the moon, symbol of the woman and the horse (here the ponytail), symbol of the man.

In order to reflect the shape of the Mygale spider, only four trigrams have been taken into account, these include TOUEI or TUI, SOUEN, TCHEN, KEN. Depending on their meaning in Chinese culture, we found equivalences in Bamileke culture in order to appropriate them. Thus, the kè and the divinatory symbol (whether it originates from China or from the people of whom this subject speaks) are inseparable from each other. In the Bamileke, kè represents transcendent and dynamic forces, diffuse energy, and the 
divine power of life and fertility [31].

Given its distant origin, the ponytail in the culture of the Bamileke is a reminiscent of art conglomerated together with cowries [32]. It is a sign of bravery. Complementarity is reflected in the ponytail, an index of bravery in men and in the moon, a sign of fertility in women. This harmony is in line with the principle of $k e ̀$ among the Bamileke.

kè symbol, horn / arrow association

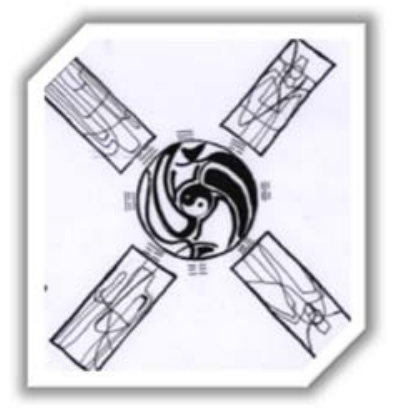

Figure 32. kè symbol, horn / arrow association, Djoukwo, 2020.

Referring to Yin-Yang, the image opposite represents the Chinese character strength, materialized by an arrow for the man and a cow horn for the woman. It must be said that this image is also inspired by the Bagua of China given the presence of the trigrams. In addition to the Chinese divinatory symbol, there is also that of the Bamileke people, inspired by the Mygale spider is a symbol of wisdom, intelligence, and foresight, that intervenes in the rites of divination.

The four members of this symbol made are covered with sketches. These sketches obtained from the fusion of Bamileke elements to which the Bagua trigrams correspond. The arrow by its nature alludes to strength, conquest, battle, and therefore victory. The cow is nourishing, protective, the prototype of the woman. Among the Bamileke, its horn, very often decorated, is a common object. It is used for drinking water or any other drinks.

This symbol can be associated with the rituals of kè insofar as it could have the power to detect evil forces and drive them out, that is to cure. Powers that we recognize in the Mygale spider as well as in Bagua through the practice of Feng Shui [33].

\subsection{Representation of Symbols on Some Art Objects Associated with kè}

The case of beef horn

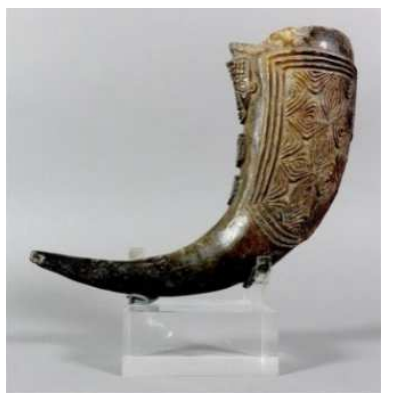

Figure 33. Horn used by Bamileke people.

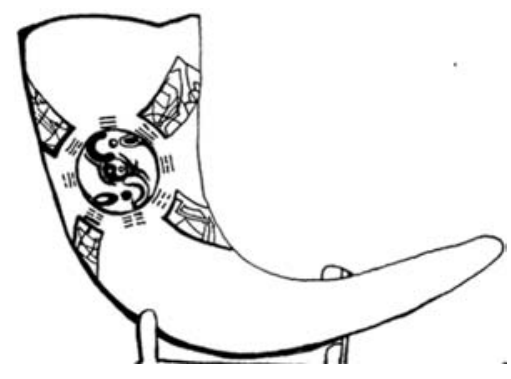

Figure 34. Horn with kè symbol, Djoukwo, 2020.

Ponytail case

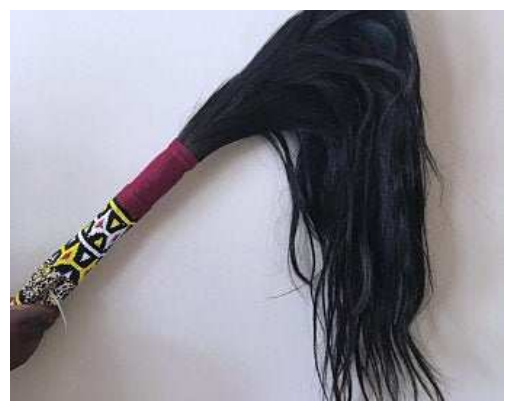

Figure 35. Bamileke ponytail.

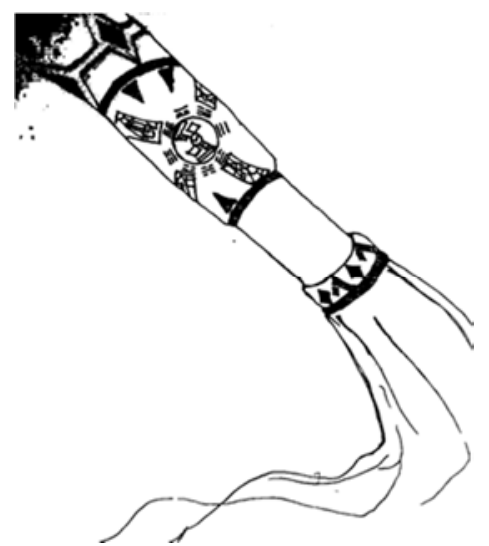

Figure 36. Ponytail with decoration of kè symbol, Djoukwo, 2020.

Example of the Bamileke elephant mask

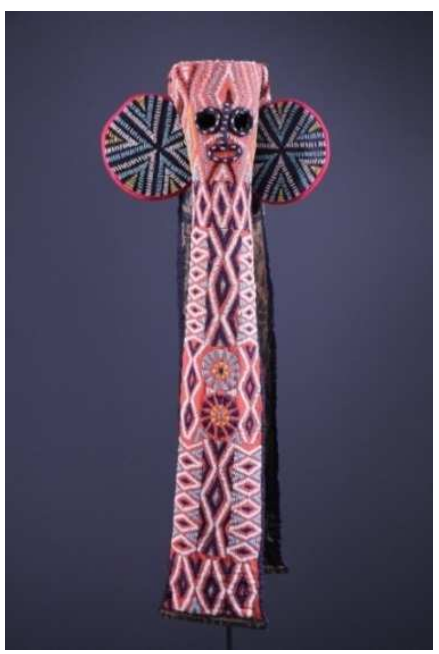

Figure 37. Mask of elephant Bamileke. 


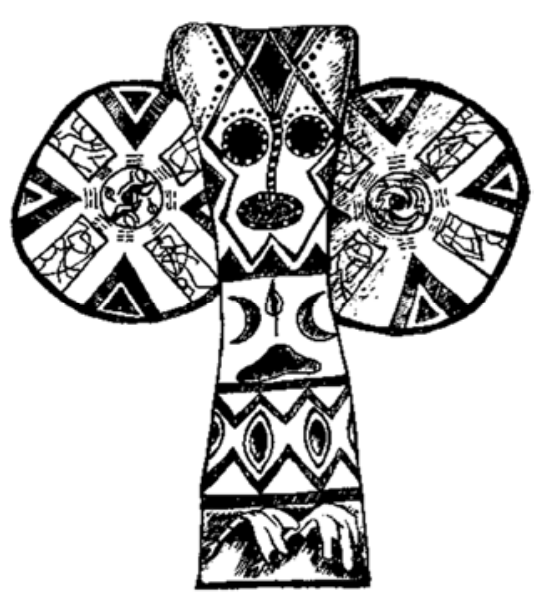

Figure 38. The kè symbol on the elephant mask, Djoukwo, 2020.

The case of body paint with the symbol kè.

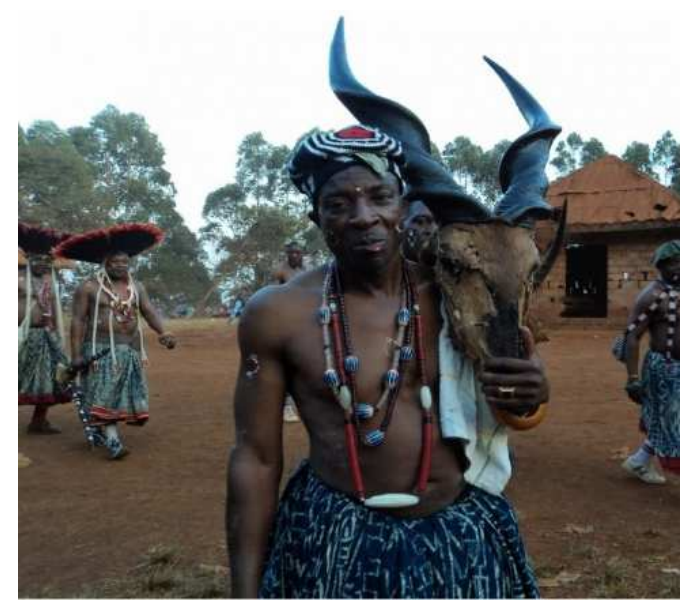

Figure 39. Member of a secretive society during kè festivities.

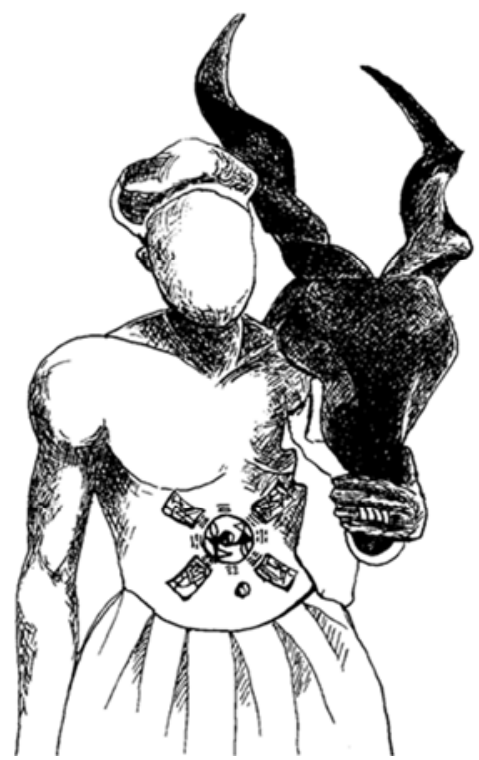

Figure 40. Body painting illustration, Djoukwo, 2020.

The case of the sacred tree in the Bamileke [34]

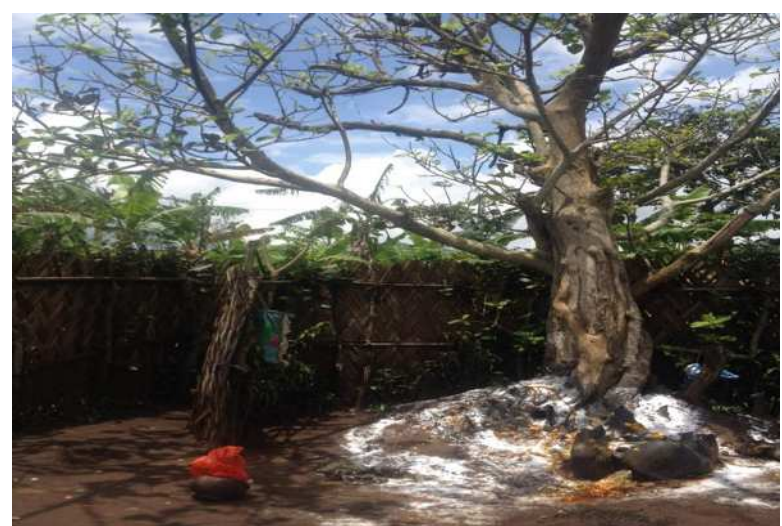

Figure 41. The Bamileke sacred tree.

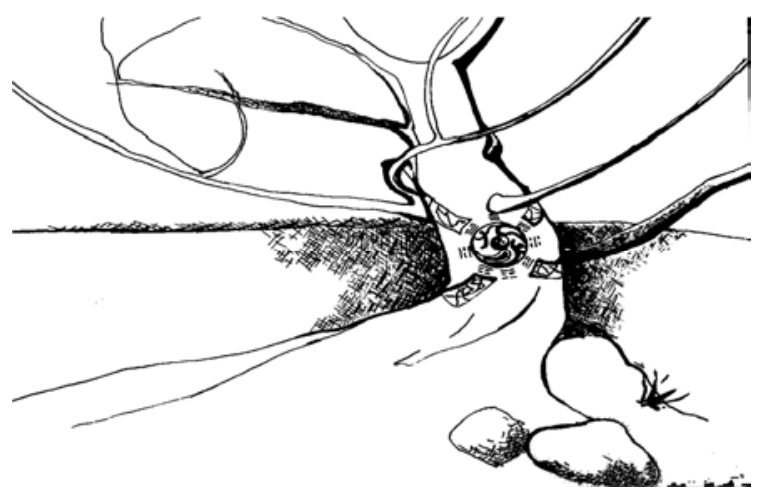

Figure 42. A sacred Bamileke tree, symbolizing kè, Djoukwo, 2020.

Examples of bells

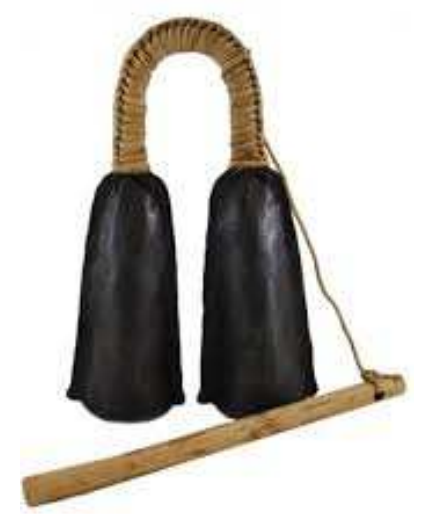

Figure 43. Bamileke double bell.

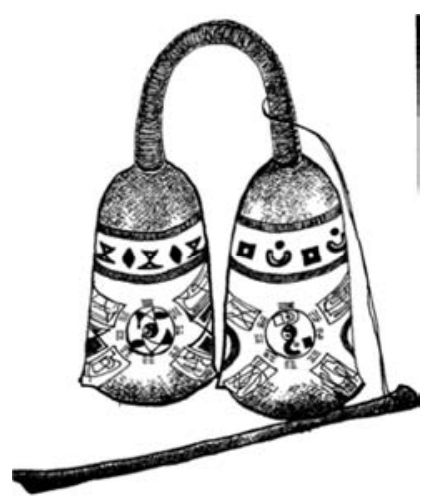

Figure 44. Bamileke double bell with kè symbol, Djoukwo, 2020. 


\section{Conclusion}

Throughout this study, it has been said that the Bamileke have a particular concept of life. They think that everything that exists in creation has an energy, a dynamic and supernatural power that can be compared to that which underlies life itself. The concentration of this power is the driving force of kè. It can increase or decrease, and it varies from one being to another, from one thing to another. Hence a hierarchy between the elements of creation in relation to the concentration of this power.

However, kè is not a figurative notion, recognizable through particular signs and symbols as is the case of the Bagua of China [35], through yin and yang by example. Nevertheless, it is still part of a well-preserved traditional concept passed down from generation to generation. Although it is an object of curiosity for many national and international researchers, it must be said that with the exception of the art objects with which this phenomenon is associated, there is no particular figurative form allowing it to be identified or even to characterize it.

In order to respond to this need for the Bamileke culture with a view to enhancing it further, we have initiated a process of artistic creation with the aim of designing symbols referring to kè. The approach was inspired by both the Bagua and the Bamileke divinatory symbol, materialized by the Mygale spider. To carry out this research, an overview was given on the concept of kè among the Bamileke ethnic group of the western region of Cameroon. It has been said that kè designates not only this power of life, this cosmic energy, but also the art or technique to manipulate it, if necessary, to increase or orient it by appropriate rituals.

Bagua $^{11}$ is an essential philosophical concept of ancient China created by Fú xī [36]. Used in Taoism [37], and but also in other areas of Chinese culture such as Feng Shui [38], martial arts [39], or navigation. In the last part, we presented the design technique of the works themselves. An in-depth study of the different trigrams offers a fairly varied repertoire of signs that can be used for an artistic conception. We have translated these signs into the Bamileke sign and symbol language in order to use them with more freedom [40]. This research could thus help to illustrate the relationship that Chinese culture maintains with the rest of the world following the thought of Danielle Tan and Caroline Grillot [41].

\section{References}

[1] Sarah Bartlett, 2018, Feng Shui Plain \& Simple: The Only Book You'll Ever Need, Copyright (C) 2010 | 2018 by Sarah Bartlett, p149.

[2] Jun Feng Li, Chun Yan Ge, Tong Luo, 2016, The Ultimate CHINESE MARTIAL ART, The Science of the weaving Stance Bagua 64 Forms and its Wellnesses Applications, World

\footnotetext{
${ }^{11}$ The school of the golden lion, Pai Liang Qiao association, was founded in 2014 by Philippe Reus, pupil of the master Hu Dong Liang, last descendant of the school of the White Lotus, Bagua.
}

Scientific, p253.

[3] Serge Augier, Philippe Lécyer, 2018, Tao Practical Encyclopaedia: Health, Energy, Meditation, Feng Shui, Yi Jing, Flammarion Quebec, p 605.

[4] Cyrille J.-D. Javary, 2018, Yin Yang: The dynamics of the world, Albin Michel.

[5] Lutang Sun \& Franklin Fick, 2018, The Study of Bagua Sword, Translated by Franklin Fick, Shen Long Publishing shenlongpub.com, p99.

[6] Jean-Charles Just, 2019, Head-to-head at Sea from China: Meetings with Masters Okinawan Martial Arts, Volume 12 to Know Martial Arts Okinawan Series, Amazon Digital Services LLC - KDP Print US, p400.

[7] DieudonneToukam, May 1, 2016, History and Anthropology of the Bamileke People: (New edition, Review and Increased), Editions L'Harmattan, p338.

[8] NTA Huligana Mwene-Larhra Shalukoma, 2004, African Law Bantu, The Spirit, p443.

[9] Christmas Lavallère Betga-Djenkwe, VI-2 2017 | 2018, Defense Technics of the West Cameroon Bamileke Chiefdoms from the Xvith to XXth century, the Diversity of African Technical Heritage, In: Journal of the History of Technology, https://do.org/10.4000/ephaistos.3289.

[10] NOTUE, J-P, 1990, The place of Kè and coronation in the arts of western Cameroon, MESIRES- ISH/ORSTOM, Yaoundé.

[11] SAVARY (C), 1980, Cameroon, arts and cultures of the peoples of the west, Museum of Ethnography, p.28.

[12] B. Kenmogne, Mr. Foka Simo, P. Charlier, 2020, Humanization of Widowhood Rites in Cameroon Using A Medical Anthropology Process: The Experience of CIPCRE, In: Ethic, Medicine and Public Health, 10.1016 / j.jemep .2019.100448.

[13] Francine Ulrich Awoung Sonkeng and Jules Kouosseu, VIII-1 | 2020, Ecomuseum: An international expansion, The Ndop" Fabric. Manufacturing Process In West Cameroon: Between Tradition and Modernity, In: Journal of the History of Technology, https://do.org/10.4000/ephaistos.7739.

[14] Josue Simo Sop, 2019, Skulls and facial masks in the funeral rites Bamileke, In: Tradition and News. Life Sciences [Q-Bio], ffdumas-02389563F.

[15] Étienne Saha Tchinda, 2017, the traditional religions of the Bamileke, Editions L'Harmattan, p236.

[16] Educational guide for teaching cultural heritage elements at Cameroonian school, 2011, heritage notebooks. Musecole Collection, Cle Editions, p130.

[17] Mburano Rwenge, 2002, Culture, Gender, Sexual Behaviors and MST / AIDS in Cameroon: Provinces of the West and Center, Training and Demographic Research Institute, $\mathrm{p} 276$.

[18] Martial Sophonie Tchetgna, 2012, Cultural and Tourist Guide of the Province of West Cameroon, Harmattan, p180.

[19] Celestin Kaffo, Chapgang Noubactep, Judith Cynthia Akamba Bekono and Hervé Tchekote, 2019, Funeral Ceremonies in the Western Cameroon: Between Changes in Societal Practices, Reconstruction of Local Economies and Spatial Planning, In: Specialities and Funeral Practices, https://do.org/10.4000/gc.12127, p. 13-32. 
[20] Wang Dongliang, January 2nd. 2020, signs and mutations: a new approach to Yi King: History, Practice and Text, Asiappy, p 336.

[21] Leopold of Saussure, 2019, the origins of Chinese astronomy: with 38 figures in the text and many sinograms. [NEW. Ed. Review and Update], Ink Book.

[22] Giovanni Maciocia, John Scott \& Co, 2018, the fundamental principles of Chinese medicine, 3rd edition, Elsevier Health Sciences, $\mathrm{p} 1388$.

[23] Minako Komatsu, 2020, my female yoga notebook, EDI8, p 107.

[24] Lu zijian, 2018, Bagua Hunyuan Yangsheng Gong, p 31.

[25] Benoît Thery, 2020, Intercultural Management in Africa: Renaissance, EMS Editions, p 204.

[26] Bernard Puepi, Henri Njomgang, 2003, Cameroon: Arts, History and Traditions, Harmattan, p 200.

[27] Celestine Colette Fouellefak Kana, 2010, religious values and sustainable development: an approach to analyzing the institutions of the Bamileke of Cameroon, African Collective Books, p131.

[28] Wikipédia/site: www.lesbantous.fr/culture.php

[29] Panofsky, E, 1939, Essays of Iconology, the Work of Art and its Meanings, p45.

[30] UNDERSTANDING CHINA, 2018, Shanghai Foreign Language education press, p339.

[31] Dongmo Temgoua Bertrand, 2019, Tradition, Modernity and
Tourism: The Funeral Transformation Bamileke into Cultural Brand to Cameroon, Rielma, Special Issue, Migration, Savings and Societies: Cultural Transfers to Identity Marketing,"Publicatie LMA Sub Egida CIL.

[32] Elliot, P, conglomerate African art, translated from English by Raoul Lehuard, in Arts of Black Africa, $\mathrm{n}^{\circ}$ 10, pp.12-41; cited by, Notué, J-P, Idem, p194.

[33] LONELY PLANET FR, 2018, Chine 12ed, edi8, p1142.

[34] Raoul Djimeli, 2019, the rite of 'Metsah' at the Bamileke, in: Sinotable.com

[35] Pierre Grosser, 2019, the history of the world is in Asia: another vision of the twentieth century, Odile Jacob.

[36] Carmelle Libli, Sylvain Kuassi, 2019, Yi-King of To-Che, Independently Published, p127.

[37] Liliane Draft, Christmas Draft, 2018, China, Encyclopes, Claude Cachin, Henri Choimet (Illustrator), Milan, p283.

[38] Carmen Folguera, 2021, the way of Yi Jing, Resources and Meaning, Editions Leduc, p192.

[39] Roland Habersetzer, 2019, Kung-Fu Practice: Beginner to Expert, Budo Editions, p589.

[40] Gaspard-Hubert LONSI KOKO, 2020, Bantu Consciousness, The Workshop of the Degreek, p166.

[41] Danielle Tan, Caroline Grillot, 2018, Southeast Asia in the Chinese Century." Cambodia, Laos and Vietnam, Traffic Observatory, Institute for Research on Southeast Asia Contemporary, p168. 